\title{
Article \\ Overexpression of Type 1 and 2 Diacylglycerol Acyltransferase Genes (JcDGAT1 and JcDGAT2) Enhances Oil Production in the Woody Perennial Biofuel Plant Jatropha curcas
}

\author{
Tian-Tian Zhang ${ }^{1,2}$, Huiying He ${ }^{2,3}$, Chuan-Jia $\mathrm{Xu}^{2} \oplus$, Qiantang $\mathrm{Fu}^{2,3}$, Yan-Bin Tao ${ }^{2,3, *}$, Ronghua $\mathrm{Xu}^{4, *}$ \\ and Zeng-Fu $\mathrm{Xu}^{2,5, *(D)}$ \\ 1 School of Life Sciences, University of Science and Technology of China, Hefei 230027, China; \\ ttzz@mail.ustc.edu.cn \\ 2 CAS Key Laboratory of Tropical Plant Resources and Sustainable Use, Xishuangbanna Tropical Botanical \\ Garden, The Innovative Academy of Seed Design, Chinese Academy of Sciences, Menglun, \\ Mengla 666303, China; hhy@xtbg.org.cn (H.H.); xuchuanjia@xtbg.ac.cn (C.-J.X.); fuqiantang@xtbg.ac.cn (Q.F.) \\ 3 Center of Economic Botany, Core Botanical Gardens, Chinese Academy of Sciences, Menglun, \\ Mengla 666303, China \\ 4 College of Life and Health Sciences, Anhui Science and Technology University, Fengyang 233100, China \\ 5 State Key Laboratory for Conservation and Utilization of Subtropical Agro-Bioresources, College of Forestry, \\ Guangxi University, Nanning 530004, China \\ * Correspondence: taoyanbin@xtbg.ac.cn (Y.-B.T.); xrh96@163.com (R.X.); zfxu@gxu.edu.cn (Z.-F.X.)
}

check for

updates

Citation: Zhang, T.-T.; He, H.; Xu, C.-J.; Fu, Q.; Tao, Y.-B.; Xu, R.; Xu, Z.-F. Overexpression of Type 1 and 2 Diacylglycerol Acyltransferase Genes (JcDGAT1 and JcDGAT2) Enhances Oil Production in the Woody Perennial Biofuel Plant Jatropha curcas. Plants 2021, 10, 699. https://doi.org/ 10.3390/plants10040699

Academic Editor: Jelli Venkatesh

Received: 3 March 2021

Accepted: 2 April 2021

Published: 5 April 2021

Publisher's Note: MDPI stays neutral with regard to jurisdictional claims in published maps and institutional affiliations.

Copyright: (c) 2021 by the authors. Licensee MDPI, Basel, Switzerland. This article is an open access article distributed under the terms and conditions of the Creative Commons Attribution (CC BY) license (https:/ / creativecommons.org/licenses/by/ $4.0 /)$.
Abstract: Diacylglycerol acyltransferase (DGAT) is the only enzyme that catalyzes the acyl-CoAdependent acylation of sn-1, 2-diacylglycerol (DAG) to form triacylglycerol (TAG). The two main types of DGAT enzymes in the woody perennial biofuel plant Jatropha curcas, JcDGAT1 and JcDGAT2, were previously characterized only in heterologous systems. In this study, we investigated the functions of JcDGAT1 and JcDGAT2 in J. curcas. JcDGAT1 and JcDGAT2 were found to be predominantly expressed during the late stages of J. curcas seed development, in which large amounts of oil accumulated. As expected, overexpression of JcDGAT1 or JcDGAT2 under the control of the CaMV35S promoter gave rise to an increase in seed kernel oil production, reaching a content of $53.7 \%$ and $55.7 \%$ of the seed kernel dry weight, respectively, which were respectively $25 \%$ and $29.6 \%$ higher than that of control plants. The increase in seed oil content was accompanied by decreases in the contents of protein and soluble sugars in the seeds. Simultaneously, there was a two- to four-fold higher leaf TAG content in transgenic plants than in control plants. Moreover, by analysis of the fatty acid (FA) profiles, we found that JCDGAT1 and JCDGAT2 had the same substrate specificity with preferences for C18:2 in seed TAGs, and C16:0, C18:0, and C18:1 in leaf TAGs. Therefore, our study confirms the important role of JcDGAT1 and JcDGAT2 in regulating oil production in J. curcas.

Keywords: J. curcas; oil content; TAG; fatty acid; seed kernels; leaves

\section{Introduction}

Jatropha curcas L., belonging to the Euphorbiaceae family, is a perennial woody biofuel plant with great environmental adaptability [1,2]. The oil content of $J$. curcas seed kernels from different regions and altitudes ranges from $40 \%$ to $55 \%$ [3-5], and its major fatty acids (FAs) are palmitic acid (14\%), stearic acid (7\%), oleic acid (44\%) and linoleic acid (32\%) [6]. Such profiles of kernel oil with high amounts of monounsaturated and polyunsaturated FAs determine its semi-drying property and make it suitable as an efficient substitute for diesel fuel $[2,6]$. However, unsatisfied seed and oil yields and low economic returns limit the application of J. curcas in the biodiesel industry [7-9]. Therefore, breeding for high J. curcas oil yield by genetic improvement has great potential for future biodiesel production.

Triacylglycerols (TAGs), which are composed of three FA chains esterified to a glycerol backbone, are the major component of plant seed oil [10]. The formation of TAGs generally 
consists of two processes: FA synthesis in plastids and TAG assembly in the endoplasmic reticulum [11]. Diacylglycerol acyltransferase (DGAT), which is considered to be a crucial enzyme for TAG biosynthesis, catalyzes the acylation of the sn-3 position of DAG to form TAG in the last step in the Kennedy pathway [12]. DGAT1 and DGAT2 are two main types of DGAT enzymes identified in eukaryotes [13]. Although both of these enzymes are endoplasmic reticulum membrane-bound enzymes, evolutionary analyses demonstrated that DGAT1 and DGAT2 evolved separately and belonged to unrelated families with respect to protein sequence and structure $[13,14]$. For instance, DGAT1 contains 8-10 transmembrane domains, whereas DGAT2 contains only two such domains $[12,13,15]$.

DGAT1 and DGAT2, which encode the two types of DGAT, are probably the most extensively studied genes for modifying oil production in plant species $[12,16,17]$. The expression levels of DGAT1 and DGAT2 were normally correlated with TAG accumulation. In Arabidopsis, AtDGAT1 rather than AtDGAT2 contributes to TAG accumulation in seeds, which was revealed by upregulation and mutational downregulation studies $[18,19]$. However, transient expression of AtDGAT2 in tobacco leaves gave rise to an increase in the TAG content to levels twice as high as that resulting from the parallel expression of $A t$ DGAT1 [20]. AtDGAT1 might have effects that favor TAG accumulation in seeds, whereas AtDGAT2 may be more important for TAG accumulation in vegetative tissues. Many additional studies reported that DGAT1 plays an important role in oil production [21-25]. However, GmDGAT2D from soybean (Glycine max) and PtDGAT2B from Phaeodactylum tricornutum could increase the oil content, as GmDGAT1 and PtDGAT1 did [26-29]. Particularly, in Cyperus esculentus, whose tuber is a lipid storage organ, it seems that only CeDGAT2 $b$ contributes to TAG accumulation because CeDGAT1 and CeDGAT2 $a$ failed to restore the TAG-deficient phenotypes of yeast and Arabidopsis and increase the TAG content in wild-type Arabidopsis [30].

In addition to the modification of oil content, DGAT1 and DGAT2 can affect the FA compositions of TAGs with different substrate preferences. DGAT1 incorporates the usual FAs such as palmitic acid, stearic acid, oleic acid and linoleic acid into TAGs, whereas DGAT2 prefers unusual FAs. For example, Ricinus communis RcDGAT2 successfully increased the amount of hydroxy FA (HFA) that constitutes ricinoleic acid in Arabidopsis, whereas RcDGAT1 failed [31]. Similarly, DGAT2 from the tung tree (Vernicia fordii) rather than $D G A T 1$ could give rise to a substantial increase in eleostearic acid, the major component of tung oil, in yeast and Arabidopsis leaves [15,32]. VgDGAT2 from Vernonia galamensis had a much greater impact on vernolic acid accumulation in soybean seeds than VgDGAT1 [33]. Therefore, DGAT2 plays an essential role in unusual TAG synthesis.

JcDGAT1 and JcDGAT2 from J. curcas have been characterized in yeast, tobacco, and Arabidopsis systems, demonstrating that they function effectively in TAG biosynthesis $[34,35]$. In this study, JcDGAT1 and JcDGAT2 were overexpressed in J. curcas under the control of the CaMV $35 S$ promoter to enhance oil production. The results showed that the total oil production in the seed kernels and leaves was significantly increased in the JcDGAT1- and JcDGAT2-overexpressing J. curcas plants. However, in terms of FA profiles, different alterations occurred between the seed kernels and leaves of JcDGATsoverexpressing J. curcas, and no difference between the two types of transgenic plants was found.

\section{Results}

\subsection{JcDGAT1 and JcDGAT2 are Highly Expressed at the Late Stages of Seed Development}

To analyze the expression patterns of JcDGAT1 and JcDGAT2 in wild-type J. curcas, quantitative real-time PCR (qRT-PCR) was performed using total RNA extracted from various tissues from adult J. curcas, including roots, stems, young and mature leaves, female and male flowers, green pericarps, and seeds at different developmental stages in which seeds matured at 49 days after pollination (DAP). As shown in Figure 1, both JcDGAT1 and JcDGAT2 were highly expressed in the seeds at 42 and 49 DAP and constitutively expressed in other tissues at much lower levels. The results indicate that both JcDGATs 
may be important for seed oil accumulation because the oil content increases remarkably at the late stages during seed development [3].

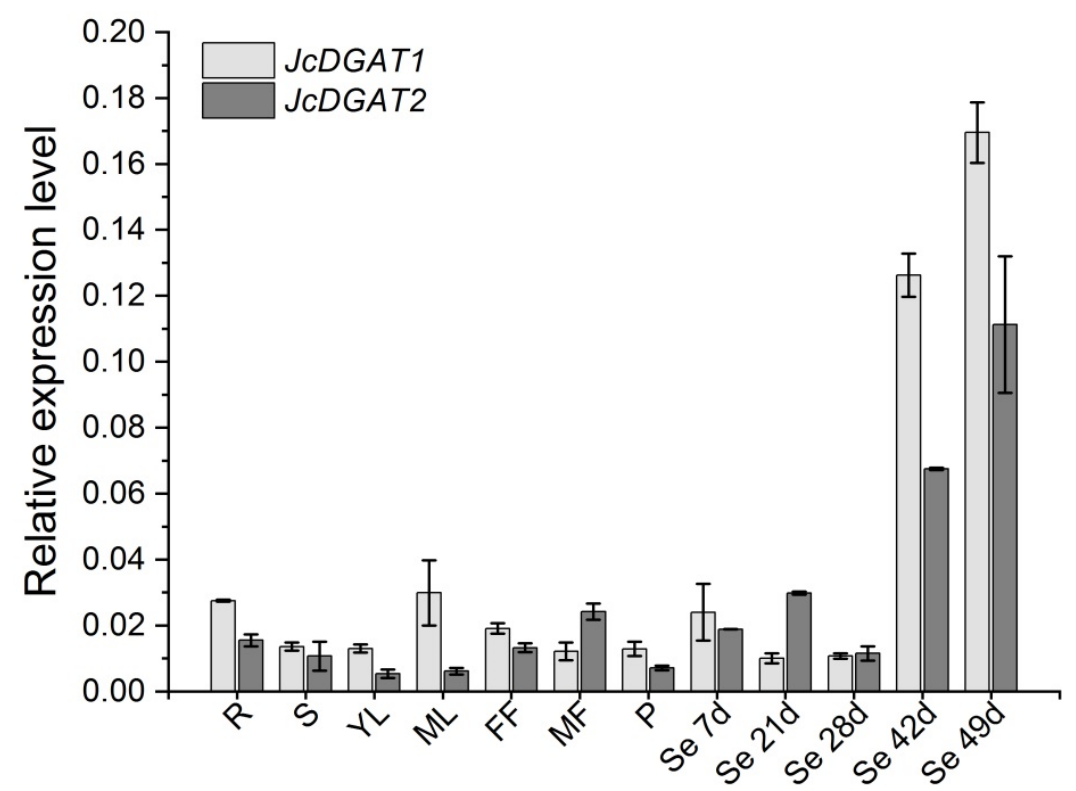

Figure 1. Expression patterns of $J c D G A T 1$ and $J c D G A T 2$ in J. curcas. The expression levels of $J c D G A T 1$ and JCDGAT2 were analyzed in the roots (R), stems (S), young leaves (YL), mature leaves (ML), female flowers (FF), male flowers (MF), green pericarps (P), and seeds at 7, 21, 28, 42 and 49 days after pollination (DAP) (Se $7 \mathrm{~d}, 21 \mathrm{~d}, 28 \mathrm{~d}, 42 \mathrm{~d}$ and $49 \mathrm{~d}$, respectively). The qRT-PCR results were obtained from two independent biological replicates and three technical replicates. The levels were normalized using the amplified products of JcActin1. The values are presented as the means \pm standard deviations.

\subsection{Overexpression of JcDGAT1 and JcDGAT2 Enhanced Seed Oil Production in Transgenic J. curcas}

To understand whether the two JcDGATs can affect native oil production, both genes driven by the CaMV35S promoter were transformed into J. curcas. The obtained transgenic plants did not exhibit any morphological changes compared with the control plants harboring a construct of $\beta$-glucuronidase (GUS) driven by the constitutive JcUEP promoter (JcUEP:GUS) [36]. In total, we generated 19 independent 35S:JcDGAT1 and 18 independent 35S:JcDGAT2 transgenic J. curcas lines, which were identified by the PCR detection of 35S:JCDGATs fragments (Figure S1). After J. curcas plants were fully mature, the T1 seeds were harvested and appeared normal relative to the control seeds (Figure 2A). The expression levels of JcDGAT1 and JcDGAT2 were significantly increased in the transgenic seeds (Figure 2B). Then, we detected the seed kernel oil contents of five independent transgenic lines from each transgenic type. Compared with control plants, the total kernel oil contents in all tested transgenic lines were increased (Figure 3A), with no significant difference in the seed dry weight (Figure 3B). The 35S:JcDGAT1 and 35S:JcDGAT2 transgenic lines accumulated $13.8 \%$ to $25 \%$ and $18.9 \%$ to $29.6 \%$ more kernel oil, respectively. This result indicated that both JcDGAT1 and JcDGAT2 were able to promote seed oil production in J. curcas. Additionally, we found that the increase in seed oil contents were positively correlated with the expression levels of JcDGAT1 and JcDGAT2. L36 and L40 from 35S:JCDGAT1 transgenic lines and L51 and L31 from 35S:JcDGAT2 transgenic lines, which exhibited intermediate and high expression levels of transgenes, respectively, were selected for further studies. 

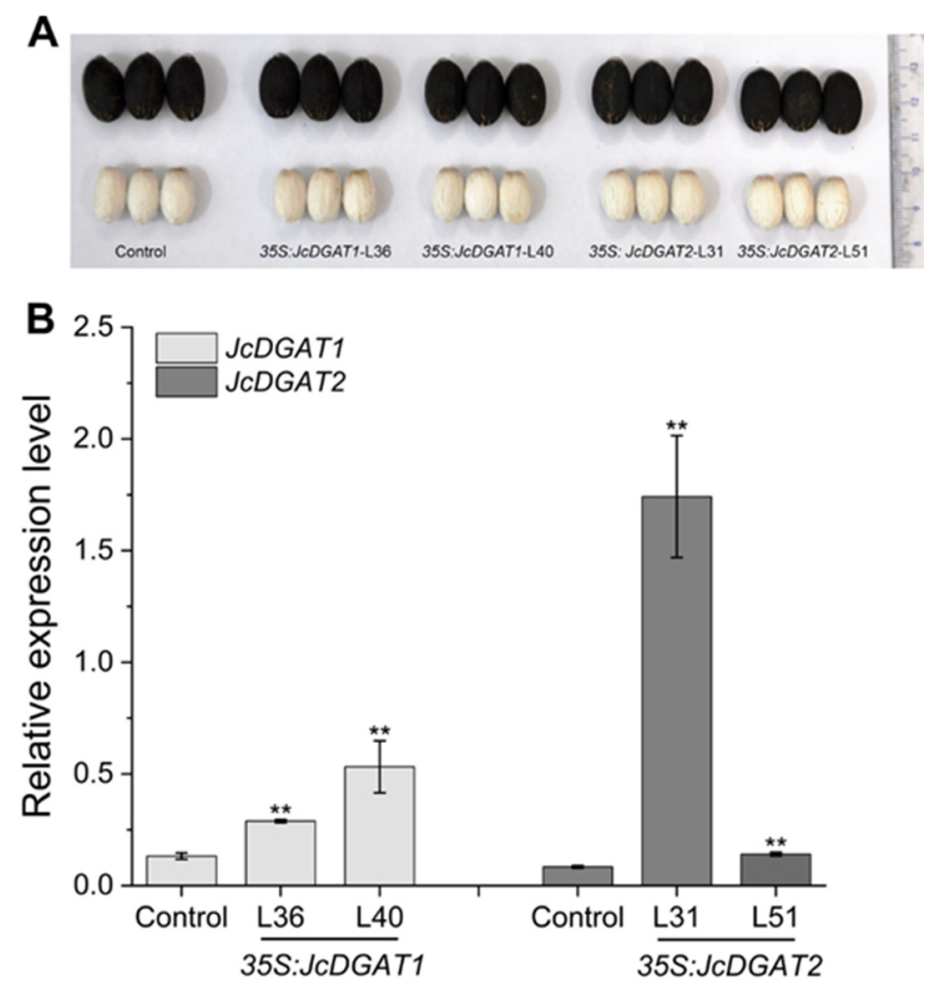

Figure 2. Appearance of seeds and kernels from 35S:JcDGATs transgenic J. curcas lines. (A) Phenotypes of seeds and kernels from control and transgenic lines. (B) The expression levels of JcDGAT1 and JcDGAT2 in the control and 35S:JcDGATs transgenic seed kernels. The expression levels were normalized using the amplified products of the JcActin1. The values are presented as the mean \pm standard deviations $(n=3)$. The student's t-test was used for statistical analyses. ${ }^{* *} p \leq 0.01$.
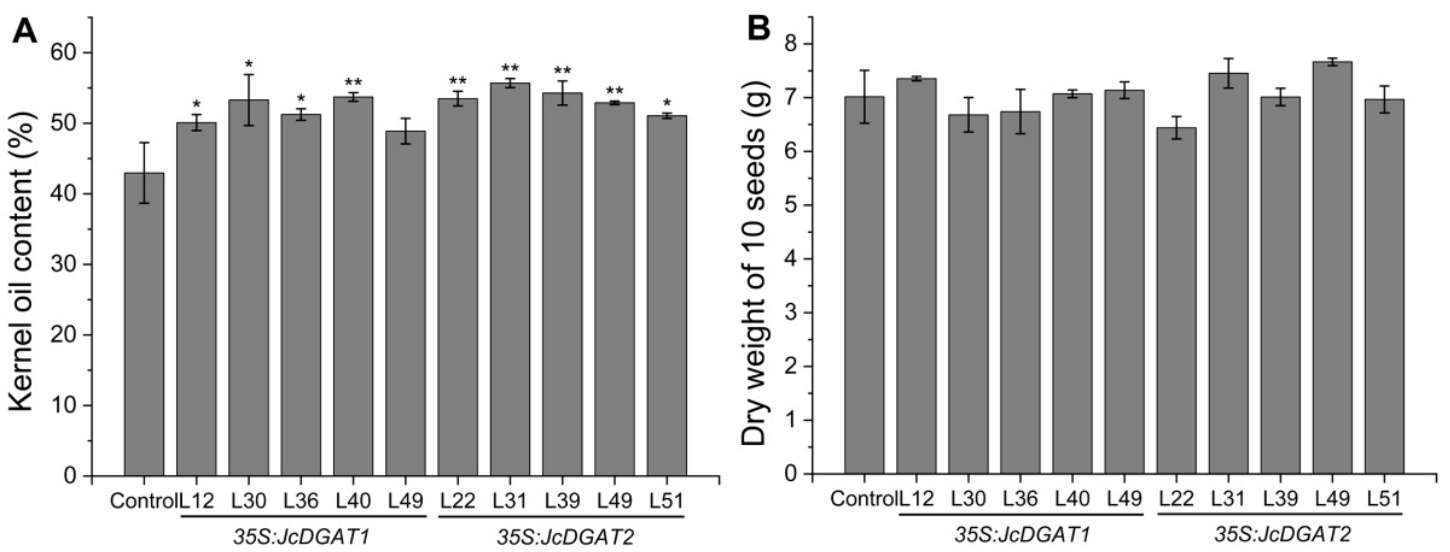

Figure 3. Seed kernel oil contents and dry weights in control and 35S:JcDGATs transgenic lines. (A) Total kernel oil content. (B) Dry weight of 10 seeds. The values are presented as the means \pm standard deviations of three independent biological replicates. The student's t-test was used for statistical analyses. ${ }^{*} p \leq 0.05,{ }^{* *} p \leq 0.01$.

In addition, we examined the protein, starch, and soluble sugar contents in the seeds from 35S:JCDGATs transgenic lines to determine possible changes in other metabolites along with the increased oil content. The results showed that the increase in seed oil content was primarily compensated by decreases in the protein and soluble sugar contents in both transgenic events (Table 1). The starch content in transgenic lines was not significantly different from that in the control, except for the decrease in the 35S:JcDGAT1 transgenic line L40. The greater the increase in the oil content was, the more the contents of other metabolites decreased. 
Table 1. Content of major metabolites in the seed kernels from the control and 35S:JcDGATs transgenic J. curcas plants.

\begin{tabular}{|c|c|c|c|c|}
\hline Genotype & $\begin{array}{c}\text { Oil } \\
(\%, w / w)\end{array}$ & $\begin{array}{l}\text { Protein } \\
(\%, w / w)\end{array}$ & $\begin{array}{l}\text { Starch } \\
(\%, w / w)\end{array}$ & $\begin{array}{l}\text { Soluble Sugar } \\
\quad(\%, w / w)\end{array}$ \\
\hline Control & $42.97 \pm 4.29$ & $19.15 \pm 0.95$ & $5.95 \pm 0.93$ & $3.15 \pm 0.18$ \\
\hline 35S:JcDGAT1-L36 & $51.25 \pm 0.82 *$ & $17.24 \pm 2.63$ & $6.06 \pm 1.20$ & $2.96 \pm 0.01$ \\
\hline 35S:JcDGAT1-L40 & $53.73 \pm 0.61 * *$ & $15.61 \pm 0.26^{* *}$ & $4.65 \pm 0.52$ & $2.17 \pm 0.14^{* *}$ \\
\hline 35S:JcDGAT2-L31 & $55.70 \pm 0.64^{* *}$ & $15.83 \pm 0.60 * *$ & $5.32 \pm 0.93$ & $2.79 \pm 0.42$ \\
\hline 35S:JcDGAT2-L51 & $51.07 \pm 0.37^{*}$ & $17.66 \pm 0.89$ & $6.03 \pm 1.01$ & $2.88 \pm 0.20$ \\
\hline
\end{tabular}

The values represent the means $\pm \mathrm{SD}(n=3)$. The student's $t$-test was used for statistical analyses. ${ }^{*} p \leq 0.05$, ** $p \leq 0.01$.

\subsection{FA Compositions Significantly Changed in Seed Oil of Transgenic J. curcas}

Since the oil contents in transgenic lines were increased, we assumed that the FA compositions would also be changed. Therefore, four major FAs in J. curcas seed oil, palmitic acid (C16:0), stearic acid (C18:0), oleic acid (C18:1) and linoleic acid (C18:2) [37], were detected by gas chromatography flame ionization detection (GC-FID). The results showed a shift from saturated FAs (SFAs, C16:0 and C18:0) and monounsaturated FAs (MUFAs, C18:1) towards polyunsaturated FAs (PUFAs, C18:2) in the transgenic lines when compared with control plants (Figure 4). In 35S:JcDGAT1 transgenic lines, the contents of C16:0, C18:0 and C18:1 were reduced on average by $16 \%, 18 \%$ and $10 \%$, respectively, but that of C18:2 was increased on average by 33\%. In 35S:JCDGAT2 transgenic lines, the C16:0, C18:0 and C18:1 contents were reduced on average by $9 \%, 49 \%$ and $17 \%$, whereas that of C18:2 was increased on average by $46 \%$. The results reveal that JcDGAT1 and JcDGAT2 had a similar effect on the FA profiles in J. curcas seed oil with a preference of using C18:2 as the acyl donor. In summary, overexpression of $J c D G A T$ s resulted in a decrease in the saturation level and an increase in the unsaturation level.

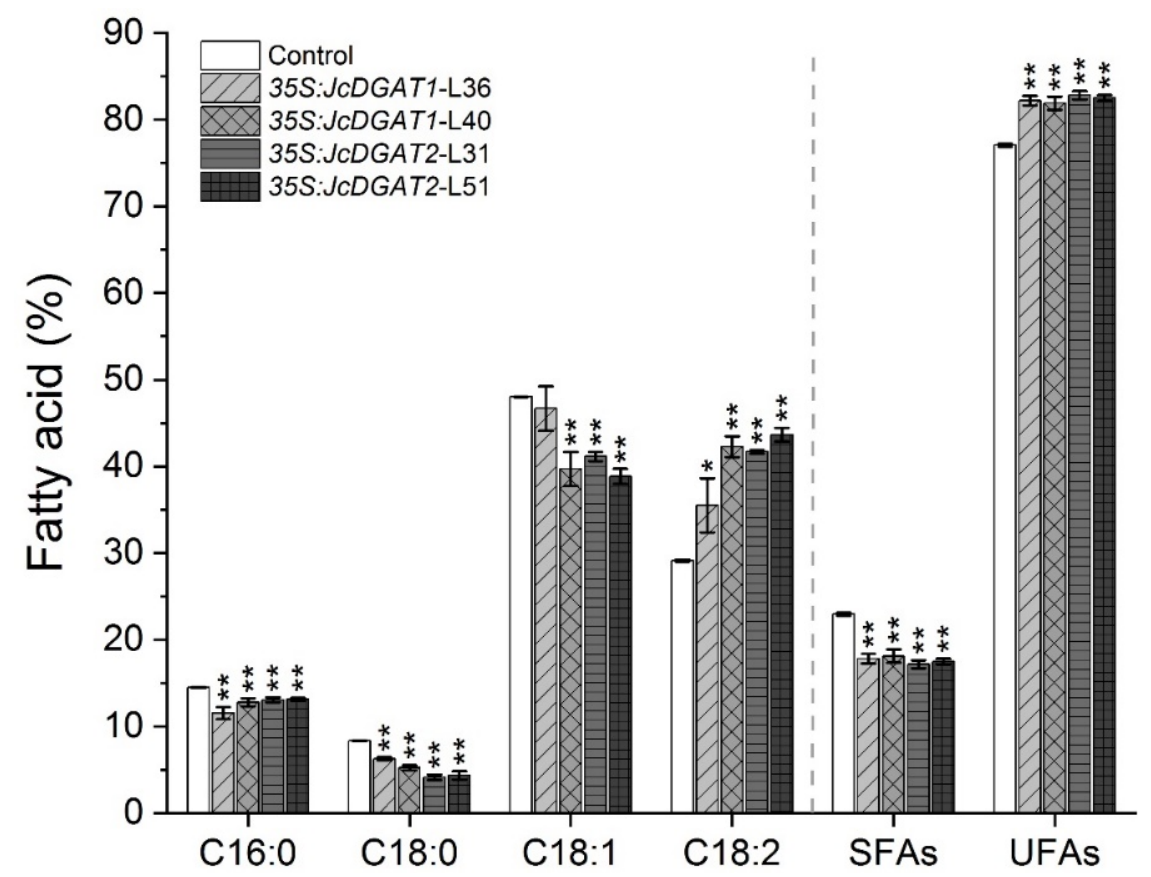

Figure 4. Fatty acid (FA) profiles of seed kernel oil in control and transgenic J. curcas. Saturated FAs (SFAs) indicate the sum of the contents of C16:0 and C18:0, and unsaturated FAs (UFAs) indicate the sum of the contents of C18:1 and C18:2. The values are presented as the mean \pm standard deviation of three biological replicates. The student's $t$-test was used for statistical analyses. ${ }^{*} p \leq 0.05,{ }^{* *} p \leq 0.01$. 


\subsection{Overexpression of JcDGAT1 and JcDGAT2 Altered TAG Accumulation and FA Compositions} in Transgenic J. curcas Leaves

Furthermore, we investigated the effect of JcDGATs on TAG synthesis in leaves. Total lipids extracted from the fully expanded green leaves (Figure 5A), in which the expression levels of transgenes were also significantly increased (Figure 5B), were analyzed for the separation of TAGs using thin-layer chromatography (TLC) (Figure S2). After TAG quantification by GC-FID, we found that the TAG contents in leaves of transgenic lines were higher than those in control plants (Figure 5C). The highest TAG content of $170 \mathrm{\mu g} / 100 \mathrm{mg}$ dry weight detected in the leaves from the 35S:JcDGAT1 transgenic line L36 was almost four times that of the control $(43 \mu \mathrm{g} / 100 \mathrm{mg})$, which was consistent with the TLC results showing that L36 exhibited the most intense TAG spot (Figure S2). The TAG contents in the other transgenic lines increased by an average of two times compared to that of the control.

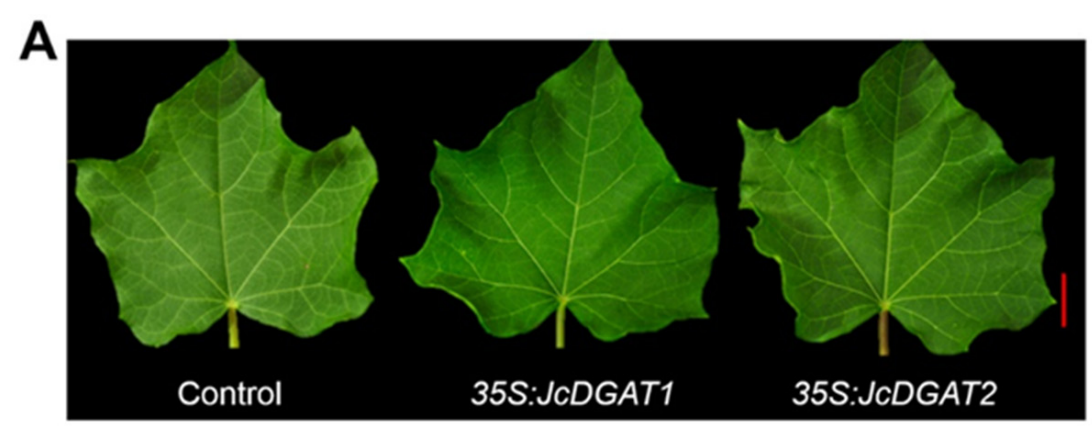

B

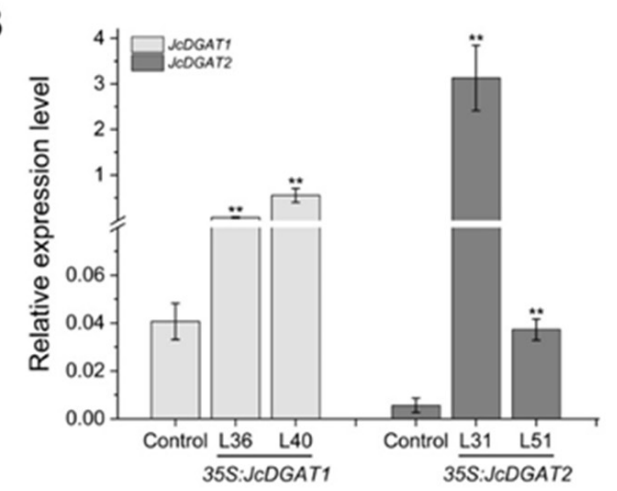

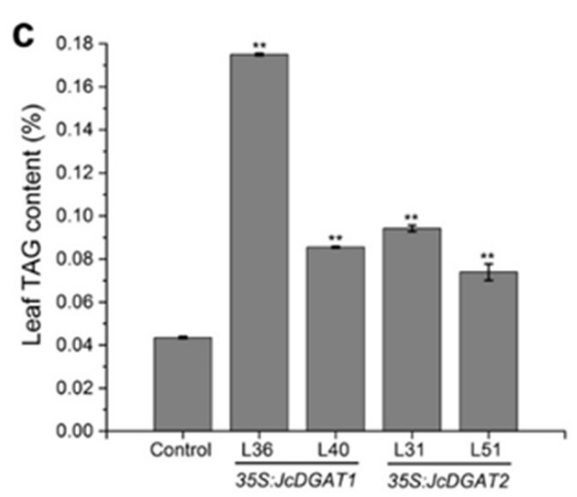

Figure 5. Triacylglycerol (TAG) contents accumulated in transgenic lines with normal phenotypes. (A) Phenotypes of leaves from the control and transgenic plants during the period of fruiting. Scale bar $=2 \mathrm{~cm}$. (B) The expression levels of JcDGAT1 and JcDGAT2 in the control and 35S:JcDGATs transgenic leaves. (C) TAG contents in the leaves of control and transgenic plants. The values are presented as the mean \pm standard deviation of two biological replicates. The student's $t$-test was used for statistical analyses. ${ }^{* *} p \leq 0.01$.

In addition, compared with the control, the FA compositions of TAGs in transgenic plants were significantly altered (Figure 6). The contents of C16:0, C18:0 and C18:1 in all transgenic lines were markedly increased except in the 35S:JcDGAT2 transgenic line L51. The alterations in these three FAs were contrary to those in seed oil. The C18:2 contents in 35S:JcDGAT1 transgenic line L40 and 35S:JcDGAT2 transgenic line L51 were also increased. These increased FAs were at the expense of $\mathrm{C} 16: 1, \mathrm{C} 18: 3$ and other FAs. The results indicate that JcDGAT1 and JcDGAT2 preferred to use C16:0, C18:0 and C18:1 as acyl donors in leaf TAG synthesis. 


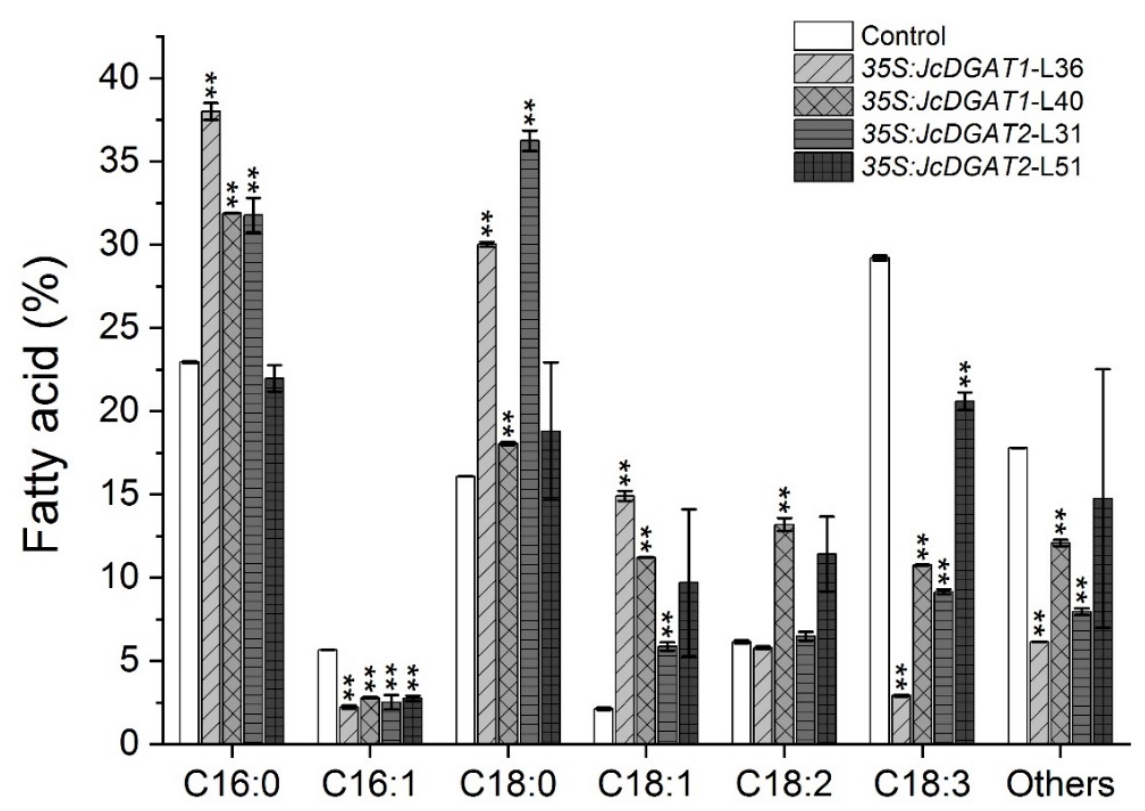

Figure 6. FA profile of TAGs in the leaves of control and transgenic plants. The values are presented as the mean \pm standard deviation of two biological replicates. The student's $t$-test was used for statistical analyses. ${ }^{* *} p \leq 0.01$.

\section{Discussion}

DGAT, which catalyzes the last step in the Kennedy pathway, is especially important for TAG accumulation. Although there are at least four types of DGATs [38,39], type 1 and type 2 DGATs are reported to contribute to TAG synthesis in most plant species. In J. curcas, three DGAT genes, JcDGAT1, JcDGAT2, and JcDGAT3, have been identified [37,40], in which JcDGAT1 and JcDGAT2 have been proven to affect oil accumulation in Arabidopsis and tobacco $[34,35]$. In addition, virus-induced gene silencing of a transcription factor JcMYB1 in J. curcas leaves down-regulated the expression of $J c D G A T 1$, resulting in a reduction in the lipid content [41]. In the current study, JcDGAT1 and JcDGAT2 were overexpressed in J. curcas to improve the oil yield. Oil contents were increased by approximately $25 \%$ and $29.6 \%$ in seed kernels (Figure $3 \mathrm{~A}$ and Table 1) and four- and two-fold in leaves (Figure 5C) of JcDGAT1- and JcDGAT2-overexpressing J. curcas, respectively. Our results demonstrate that both JcDGAT1 and JcDGAT2 play an effective role in lipid accumulation and perform similar functions in seeds and leaves. Our conclusions further support the results from the heterologous overexpression of JcDGAT1 and JcDGAT2 in yeast and tobacco by $\mathrm{Xu}$ et al. [34]. Similar to the functions of JcDGAT1 and JcDGAT2, GmDGAT1A and GmDGAT2D from soybeans can both promote TAG accumulation in soybean hairy roots [28]. The similar role in oil accumulation of the two types of DGAT genes from J. curcas and soybean is associated with their similar expression patterns. Transcripts of GmDGAT1A and GmDGAT2D were both found in soybean roots [27,28]. In J. curcas, JcDGAT1 and $J c D G A T 2$ were both expressed in the seeds and leaves (Figure 1). Moreover, the increases in expression levels of JcDGAT1 and JcDGAT2 in transgenic J. curcas were higher in leaves (Figure $5 \mathrm{~B}$ ) than in seeds (Figure 2B), which indicated the 355 promoter was more active in mature leaves than in mature seeds. Our results show that the kernel oil content increased along with the reduction in the contents of other major metabolites to varying degrees and did so significantly in 35S:JcDGAT1 transgenic line L40 and 35S:JcDGAT2 transgenic line L31, in which the protein contents decreased by $18 \%$ and $17 \%$ and the soluble sugar contents decreased by $31 \%$ and $11 \%$, respectively, compared with the contents in the control lines (Table 1). During seed maturation, carbon and nitrogen are present in three main forms: TAGs, carbohydrates, and proteins [42]. Many studies have shown that the flow of carbon determines the accumulation of these three types of compounds [43,44]. Sugar produces pyruvate, the precursor of acetyl-CoA, through glycolysis, and pyruvate plays a 
central role in the production of TAGs, starch, and amino acids. The greater carbon flux into the lipid metabolism pathway in JcDGATs-overexpressing plants resulted in higher TAG contents, which must be accompanied by a reduction in protein and sugar contents. It has been shown that DGAT not only incorporates the substrate into TAGs but also increases the flow of products from the upstream glycolytic pathway to lipid synthesis [45]. Therefore, this indicates that the accumulation of oil can be increased by enhancing de novo FA synthesis, such as through the overexpression of WRI1, which can regulate the allocation of carbon between carbohydrates and storage lipids, or by the prevention of starch or protein formation from pyruvate, such as downregulation of ADP-glucose pyrophosphorylase, whichis a rate-limiting enzyme for starch synthesis [46,47].

Our data also indicate that JcDGAT1 and JcDGAT2 have similar effects on the FA profiles of seed oil. In both JcDGAT1- and JcDGAT2-overexpressing lines, the percentage of C18:2 significantly increased at the expense of C16:0, C18:0 and C18:1 (Figure 4), suggesting that both JcDGAT1 and JcDGAT2 have a substrate preference for linoleic acid. In JcDGATsoverexpressing tobacco, however, JcDGAT1 did not induce changes in FA compositions, whereas JcDGAT2 overexpression led to a significant increase in the proportion of C18:2 [34]. In Arabidopsis seeds, the expression of JcDGAT1 did not affect SFAs but increased the percentages of C18:3 and C18:2 largely at the expense of C18:1 [35]. The variation in FA composition induced by DGAT genes may be caused by different substrates and selectivity in distinct species. For example, overexpression of Sesamum indicum SiDGAT1 in Arabidopsis and soybean seeds also showed different changes in FA compositions [22]. In addition, we noted a significant increase in the proportion of UFAs and a reduction in SFAs in JcDGATs transgenic seeds (Figure 4). The degree of (un)saturation of kernel oil is important for determining biodiesel oxidative stability and performance properties [48]. A high level of polyunsaturated FAs, such as linoleic acid, can reduce the stability of biodiesel due to its susceptibility to oxidation and is not ideal for biodiesel applications [48]. However, vegetable oils rich in oleic acid, which contain one double bond, can be better used as raw materials for biodiesel, and oil that is high in oleic acid and low in SFAs can improve the oxidation stability while increasing the cold flow performance [49-51]. Therefore, based on our results, we expect to further improve the quality of $J$. curcas seed oil by increasing the proportion of oleic acid. Previous reports showed that the percentage of C18:1 was increased to 50-60\% in JcFAD2-1 RNAi transgenic J. curcas endosperm [52]. Hence, we speculate that silencing the JcFAD2 gene in JcDGATs-overexpressing J. curcas may result in an improvement in both the quality and yield of seed oil.

Moreover, overexpression of JcDGA1 and JcDGAT2 in J. curcas leaves caused significant alterations in the FA profiles of TAGs. Both JcDGAT1 and JcDGAT2 preferred to incorporate the C16:0, C18:0 and C18:1 FAs but excluded C18:3 and C16:1 into TAGs in transgenic leaves (Figure 6). Such changes in C18:3 conversion to C18:1 were also observed in J. curcas leaves with overexpression of AtDGAT1 [53]. However, compared to AtDGAT1, JcDGATs had a better effect on the production of C18:1 in the leaves of $J$. curcas (increased by 1.3 to 6-fold compared with 20-31\%). The alterations of FA compositions in the TAGs of JcDGATs-overexpressing transgenic leaves seem to be favorable for biodiesel feedstock. C16:1 was enriched in the phosphatidylglycerol (PG) component of the photosynthetic membranes [54]. Our results show that C16:1 was significantly reduced, which seems to indicate that JcDGAT1 and JcDGAT2 are also active in the chloroplast membrane at the leaves' maturity [55] but play a role in excluding C16:1 from TAGs. Interestingly, we also observed that the changes in FA compositions in leaves were distinct from those in seed kernels. The C16:0, C18:0 and C18:1 contents increased in transgenic leaves (Figure 6) but decreased in transgenic seed kernels (Figure 4). This may be because the profiles of FAs in TAGs are determined not only by the substrate preferences of the DGATs but also by the availability of substrate pools, including acyl-CoA and DAG [12]. In most seed oils, the phosphatidylcholine (PC) backbones carrying PUFAs can be catalyzed by phospholipase D (PLD), phospholipase C (PLC) or phosphatidylcholine:diacylglycerol cholinephosphotransferase (PDCT) to form phosphatidic acid (PA) or DAG. These PC- 
derived PA or DAG will enter the Kennedy pathway to form TAG in the last step catalyzed by DGAT [44,56]. However, in J. curcas seeds, a sharp downregulation of the expression of a linoleate desaturase (FAD3) gene, which functions in the PC pool, resulted in a reduction in the biosynthesis of linolenic acid at maturity [3]. In J. curcas leaves, however, we found that the proportion of linolenic acid in total TAGs was as high as $29 \%$ in the control plants (Figure 6), indicating that the substrate pool of DGATs was different between seeds and leaves in J. curcas. In addition, a previous study suggested that leaves may have an inherent capacity for TAG synthesis compared with seeds [57]. For example, in the mutant AS11 of Arabidopsis, which affected DGAT activity, the FA profiles were significantly altered in seeds but not in leaves [58]. Thus, DGATs may have distinct effects on lipids in different tissues or different species.

Overall, we increased the oil contents of J. curcas seeds and leaves by overexpressing JcDGAT1 and JcDGAT2. This is the first study to use two types of JcDGATs to improve oil production in J. curcas. However, we need to further improve the yield and quality of oil in J. curcas to meet requirements for biodiesel feedstocks. Coexpressing JcDGATs with an antisense inhibition of JcFAD2 gene [52] in J. curcas could be a possibility for achieving better results.

\section{Materials and Methods}

\subsection{Plant Materials}

The adult J. curcas plants in this study were planted in Xishuangbanna Tropical Botanical Garden (XTBG; $21^{\circ} 54^{\prime} \mathrm{N}, 101^{\circ} 46^{\prime} \mathrm{E} ; 580 \mathrm{~m}$ in altitude) of the Chinese Academy of Sciences, Yunnan, China [9].

\subsection{Plant Transformation}

The 35S:JcDGAT1 and 35S:JcDGAT2 vectors constructed by $\mathrm{Xu}$ et al. [34] and the JcUEP:GUS vector constructed by Tao et al. [36] were transferred to Agrobacterium tumefaciens EHA105 for J. curcas transformation. The method used for J. curcas transformation was described previously by Fu et al. [59]. The transgenic plants were identified by PCR detection of 35S:JcDGATs fragments and the primers are listed in Table S1.

\section{3. $q R T-P C R$ Analysis}

The expression levels of JcDGATs in wild-type and transgenic J. curcas plants were analyzed by qRT-PCR. Total RNA was isolated [60] and reverse transcribed using the PrimeScript ${ }^{\circledR}$ RT reagent kit (TAKARA Biotechnology, Dalian, China). qRT-PCR was performed using TB Green ${ }^{\circledR}$ Premix Ex Taq ${ }^{\mathrm{TM}}$ II (TAKARA Biotechnology, Dalian, China) on a LightCycler 480II (Roche Diagnostics, Mannheim, Germany) device. All of the expression levels were normalized to the expression of JcActin1 [61]. The primers used in the qRT-PCR assay are listed in Table S1.

\subsection{Lipid Analysis}

Seed oil was extracted as described previously [62]. Mature seeds were harvested from adult J. curcas and dried to a constant weight. Ten seeds were weighed as a biological replicate. Seeds were removed from their shells and ground into a powder mixture. Oil was extracted from $100 \mathrm{mg}$ of the mixtures with hexane three times. Subsequently, the collected hexanes portions were evaporated at $42{ }^{\circ} \mathrm{C}$. The oil content of the kernels is presented as the percentage of dry weight of the kernels. This experiment was replicated three times. Since the TAG content can reach up to $97 \%$ of the oil in mature seeds [63], the total oil extracted from mature kernels was considered the TAG content in this study.

Approximately $10 \mathrm{mg}$ of the extracted oil shown above was methylated in $2 \%$ methanol$\mathrm{H}_{2} \mathrm{SO}_{4}$. Then, fatty acid methyl esters (FAMEs) were separated and detected using GC-FID (PerkinElmer Clarus 680, Singapore) equipped with a $30 \mathrm{~m} \times 0.25 \mu \mathrm{m} \times 0.32 \mathrm{~mm}$ (inner diameter) Elite-225 column (PerkinElmer, Singapore). The following temperature program was applied: $150{ }^{\circ} \mathrm{C}$ held for $3 \mathrm{~min} ; 10^{\circ} \mathrm{C} / \mathrm{min}$ increase to $180{ }^{\circ} \mathrm{C}$, held for $9 \mathrm{~min}$; and 
$5{ }^{\circ} \mathrm{C} / \mathrm{min}$ increase to $210^{\circ} \mathrm{C}$, held for $8 \mathrm{~min}$ [64]. The proportions of FAs were calculated via the peak area of each component compared to the total peak area [62].

\subsection{TAG Analysis in Leaves}

TAGs in leaves were analyzed using the method described in potato leaves [65]. Fully expanded green leaves were sampled and freeze-dried overnight. The dried leaves were divided into triplicate and weighed. Lipids were extracted in methanol/chloroform $/ 0.1 \mathrm{M}$ $\mathrm{KCl}$ (1:2:1, by volume) with a mixer mill (MM400, RETSCH Company, Germany) at 20 frequency/s for $3 \mathrm{~min}$. After centrifugation, the bottom solution was collected in a glass tube and evaporated completely. Then, the lipids were dissolved in chloroform in $1 \mu \mathrm{l} / \mathrm{mg}$ DW. A total of 30 mgof lipids was taken for TLC on a plate $(20 \mathrm{~cm} \times 20 \mathrm{~cm}$, silica gel 60 , Merck) with a hexane/diethyl ether/acetic acid solvent system (70:30:1, by volume). After spraying with primuline (Sigma) in $80 \%$ aqueous acetone, the plate was visualized under UV. TAGs were separated by scraping the corresponding silica bands. Then, the TAG fraction was transmethylated and analyzed by GC-FID as described for seed lipid analysis. For TAG quantification, triheptadecanoin (C17:0-TAG) was added as an internal standard at $1 \mu \mathrm{g} / \mathrm{mg}$ DW. The TAG content was calculated by the formula: TAG content $(\% \mathrm{DW})=$ sum of peak area of the endogenous fatty acids/peak area of internal standard $\times$ concentration of internal standard $\left(1 \mu \mathrm{g} \times 10^{-3} / \mathrm{mg}\right) \%$. The percentage of FAs in TAGs was calculated via the peak area of each component compared to the total peak area of endogenous FAs.

\subsection{Quantifications of Protein, Starch, and Soluble Sugar}

For the quantification of protein, $50 \mathrm{mg}$ of the seed kernel mixture prepared as described in Section 4.4 was homogenized in $300 \mu$ l of extraction buffer containing $50 \mathrm{mM}$ Tris- $\mathrm{HCl}$ (pH 7.5), $150 \mathrm{mM} \mathrm{NaCl}, 1 \mathrm{mM}$ EDTA, and 0.1\% Triton X-100 (w/v) [66]. Then, it was transferred to a $1.5-\mathrm{mL}$ centrifuge tube and placed at $4{ }^{\circ} \mathrm{C}$ for $30 \mathrm{~min}$. Following centrifugation at $1200 \mathrm{~g}$ for $10 \mathrm{~min}$, the supernatant was collected and analyzed using a Bradford protein assay kit (BL524A, GUANGKE Technology Company, Kunming).

The contents of starch and soluble sugar seed kernels were examined using a Starch Assay Kit (A148-1-1, ZanNa Biological Company, Kunming) and Soluble Sugar Assay Kit (QYS-234076, QIYI Biological Technology Company, Shanghai), respectively.

Supplementary Materials: The following are available online at https:/ / www.mdpi.com/article/10 .3390 / plants10040699/s1, Figure S1: Identification of transgenic J. curcas plants by PCR, Figure S2: TLC separation of neutral lipids in leaf tissues from control and transgenic J. curcas lines, Table S1: List of primers used in this study.

Author Contributions: All authors have read and agree to the published version of the manuscript. Conceptualization, Q.F., Y.-B.T., R.X. and Z.-F.X.; formal analysis, T.-T.Z.; investigation, T.-T.Z.; H.H., and C.-J.X.; project administration, H.H.; funding acquisition, R.X. and Z.-F.X.; supervision, Z.-F.X.; visualization, T.-T.Z. and Y.-B.T.; writing — original draft preparation, T.-T.Z. and Y.-B.T.; writingreview and editing, Y.-B.T. and Z.-F.X.; All authors have read and agreed to the published version of the manuscript.

Funding: This research was funded by the National Natural Science Foundation of China (31300569), and the Program of the Chinese Academy of Sciences (kfj-brsn-2018-6-008 and ZDRW-ZS-2017-2-3-2).

Institutional Review Board Statement: Not applicable.

Informed Consent Statement: Not applicable.

Data Availability Statement: All data are available in this article and in the supplementary file.

Acknowledgments: The authors thank Bo Tian (Xishuangbanna Tropical Botanical Garden) for providing the equipment of the Mixer mill. The authors gratefully acknowledge the Central Laboratory of the Xishuangbanna Tropical Botanical Garden for providing the research facilities.

Conflicts of Interest: The authors declare no conflict of interest. 


\section{References}

1. Kumar, V.; Tripathi, A.M.; Tak, P.K.; Chouhan, S. Tree or shrub Jatropha curcas L.: Biofuel and potential herb. J. Biofuels 2016, 7, 89-101. [CrossRef]

2. Abdulla, R.; Chan, E.S.; Ravindra, P. Biodiesel production from Jatropha curcas: A critical review. Crit. Rev. Biotechnol. 2011, 31, 53-64. [CrossRef] [PubMed]

3. Jiang, H.; Wu, P.; Zhang, S.; Song, C.; Chen, Y.; Li, M.; Jia, Y.; Fang, X.; Chen, F.; Wu, G. Global analysis of gene expression profiles in developing physic nut (Jatropha curcas L.) seeds. PLoS ONE 2012, 7, e36522. [CrossRef] [PubMed]

4. Vaknin, Y.; Ghanim, M.; Samra, S.; Dvash, L.; Hendelsman, E.; Eisikowitch, D.; Samocha, Y. Predicting Jatropha curcas seed-oil content, oil composition and protein content using near-infrared spectroscopy-A quick and non-destructive method. Ind. Crop. Prod. 2011, 34, 1029-1034. [CrossRef]

5. Jonas, M.; Ketlogetswe, C.; Gandure, J. Variation of Jatropha curcas seed oil content and fatty acid composition with fruit maturity stage. Heliyon 2020, 6, e03285. [CrossRef]

6. Augustus, G.D.P.S.; Jayabalana, M.; Seilerb, G.J. Evaluation and bioinduction of energy components of Jatropha curcas. Biomass Bioenergy 2002, 23, 161-164. [CrossRef]

7. Axelsson, L.; Franzén, M.; Ostwald, M.; Berndes, G.; Lakshmi, G.; Ravindranath, N.H. Jatropha cultivation in southern India: Assessing farmers' experiences. Biofuels Bioprod. Biorefin. 2012, 6, 246-256. [CrossRef]

8. Openshaw, K. A review of Jatropha curcas: An oil plant of unfulfilled promise. Biomass Bioenergy 2000, 19, 1-15. [CrossRef]

9. Pan, B.-Z.; Xu, Z.-F. Benzyladenine treatment significantly increases the seed yield of the biofuel plant Jatropha curcas. J. Plant Growth Regul. 2011, 30, 166-174. [CrossRef]

10. Barnwal, B.K.; Sharma, M.P. Prospects of biodiesel production from vegetable oils in India. Renew. Sustain. Energy Rev. 2005, 9, 363-378. [CrossRef]

11. Bates, P.D. Understanding the control of acyl flux through the lipid metabolic network of plant oil biosynthesis. Biochim. Biophys. Acta (BBA) Mol. Cell Biol. Lipids 2016, 1861, 1214-1225. [CrossRef] [PubMed]

12. Lung, S.C.; Weselake, R.J. Diacylglycerol acyltransferase: A key mediator of plant triacylglycerol synthesis. Lipids 2006, 41, 10731088. [CrossRef] [PubMed]

13. Turchetto-Zolet, A.C.; Maraschin, F.S.; de Morais, G.L.; Cagliari, A.; Andrade, C.M.B.; Marcia, M.-P.; Margis, R. Evolutionary view of acyl-CoA diacylglycerol acyltransferase (DGAT), a key enzyme in neutral lipid biosynthesis. BMC Evol. Biol. 2011, 11, 263. [CrossRef] [PubMed]

14. Cao, H. Structure-function analysis of diacylglycerol acyltransferase sequences from 70 organisms. BMC Res. Notes 2011, 4, 249. [CrossRef] [PubMed]

15. Shockey, J.M.; Gidda, S.K.; Chapital, D.C.; Kuan, J.-C.; Dhanoa, P.K.; Bland, J.M.; Rothstein, S.J.; Mullen, R.T.; Dyer, J.M. Tung tree DGAT1 and DGAT2 have nonredundant functions in triacylglycerol biosynthesis and are localized to different subdomains of the endoplasmic reticulum. Plant Cell 2006, 18, 2294-2313. [CrossRef]

16. Bhatt-Wessel, B.; Jordan, T.W.; Miller, J.H.; Peng, L. Role of DGAT enzymes in triacylglycerol metabolism. Arch. Biochem. Biophys. 2018, 655, 1-11. [CrossRef]

17. Liu, Q.; Siloto, R.M.; Lehner, R.; Stone, S.J.; Weselake, R.J. Acyl-CoA:diacylglycerol acyltransferase: Molecular biology, biochemistry and biotechnology. Prog. Lipid Res. 2012, 51, 350-377. [CrossRef]

18. Jako, C.; Kumar, A.; Wei, Y.; Zou, J.; Barton, D.L.; Giblin, E.M.; Covello, P.S.; Taylor, D.C. Seed-specific over-expression of an Arabidopsis cDNA encoding a diacylglycerol acyltransferase enhances seed oil content and seed weight. Plant Physiol. 2001, 126, 861-874. [CrossRef]

19. Zhang, M.; Fan, J.; Taylor, D.C.; Ohlrogge, J.B. DGAT1 and PDAT1 acyltransferases have overlapping functions in Arabidopsis triacylglycerol biosynthesis and are essential for normal pollen and seed development. Plant Cell 2009, 21, 3885-3901. [CrossRef]

20. Zhou, X.R.; Shrestha, P.; Yin, F.; Petrie, J.R.; Singh, S.P. AtDGAT2 is a functional acyl-CoA:diacylglycerol acyltransferase and displays different acyl-CoA substrate preferences than AtDGAT1. FEBS Lett. 2013, 587, 2371-2376. [CrossRef]

21. Weselake, R.J.; Taylor, D.C.; Rahman, M.H.; Shah, S.; Laroche, A.; McVetty, P.B.E.; Harwood, J.L. Increasing the flow of carbon into seed oil. Biotechnol. Adv. 2009, 27, 866-878. [CrossRef]

22. Wang, Z.; Huang, W.; Chang, J.; Sebastian, A.; Li, Y.; Li, H.; Wu, X.; Zhang, B.; Meng, F.; Li, W. Overexpression of SiDGAT1, a gene encoding acyl-CoA:diacylglycerol acyltransferase from Sesamum indicum L. increases oil content in transgenic Arabidopsis and soybean. Plant Cell Tissue Organ Cult. (PCTOC) 2014, 119, 399-410. [CrossRef]

23. Xu, J.; Francis, T.; Mietkiewska, E.; Giblin, E.M.; Barton, D.L.; Zhang, Y.; Zhang, M.; Taylor, D.C. Cloning and characterization of an acyl-CoA-dependent diacylglycerol acyltransferase 1 (DGAT1) gene from Tropaeolum majus, and a study of the functional motifs of the DGAT protein using site-directed mutagenesis to modify enzyme activity and oil content. Plant Biotechnol. J. 2008, 6, 799-818. [CrossRef] [PubMed]

24. Lock, Y.-Y.; Snyder, C.L.; Zhu, W.; Siloto, R.M.; Weselake, R.J.; Shah, S. Antisense suppression of type 1 diacylglycerol acyltransferase adversely affects plant development in Brassica napus. Physiol. Plant 2009, 137, 61-71. [CrossRef] [PubMed]

25. Zhang, F.-Y.; Yang, M.-F.; Xu, Y.-N. Silencing of DGAT1 in tobacco causes a reduction in seed oil content. Plant Sci. 2005, 169, 689-694. [CrossRef] 
26. Guiheneuf, F.; Leu, S.; Zarka, A.; Khozin-Goldberg, I.; Khalilov, I.; Boussiba, S. Cloning and molecular characterization of a novel acyl-CoA:diacylglycerol acyltransferase 1-like gene (PtDGAT1) from the diatom Phaeodactylum tricornutum. FEBS J. 2011, 278, 3651-3666. [CrossRef]

27. Li, R.; Hatanaka, T.; Yu, K.; Wu, Y.; Fukushige, H.; Hildebrand, D. Soybean oil biosynthesis: Role of diacylglycerol acyltransferases. Funct. Integr. Genom. 2013, 13, 99-113. [CrossRef]

28. Chen, B.; Wang, J.; Zhang, G.; Liu, J.; Manan, S.; Hu, H.; Zhao, J. Two types of soybean diacylglycerol acyltransferases are differentially involved in triacylglycerol biosynthesis and response to environmental stresses and hormones. Sci. Rep. 2016, 6, 28541. [CrossRef]

29. Haslam, R.P.; Hamilton, M.L.; Economou, C.K.; Smith, R.; Hassall, K.L.; Napier, J.A.; Sayanova, O. Overexpression of an endogenous type 2 diacylglycerol acyltransferase in the marine diatom Phaeodactylum tricornutum enhances lipid production and omega-3 long-chain polyunsaturated fatty acid content. Biotechnol. Biofuels 2020, 13, 87. [CrossRef]

30. Liu, D.; Ji, H.; Yang, Z. Functional characterization of three novel genes encoding diacylglycerol acyltransferase (DGAT) from oil-rich tubers of Cyperus esculentus. Plant Cell Physiol. 2020, 61, 118-129. [CrossRef]

31. Burgal, J.; Shockey, J.; Lu, C.; Dyer, J.; Larson, T.; Graham, I.; Browse, J. Metabolic engineering of hydroxy fatty acid production in plants: RcDGAT2 drives dramatic increases in ricinoleate levels in seed oil. Plant Biotechnol. J. 2008, 6, 819-831. [CrossRef] [PubMed]

32. Yurchenko, O.; Shockey, J.M.; Gidda, S.K.; Silver, M.I.; Chapman, K.D.; Mullen, R.T.; Dyer, J.M. Engineering the production of conjugated fatty acids in Arabidopsis thaliana leaves. Plant Biotechnol. J. 2017, 15, 1010-1023. [CrossRef]

33. Li, R.; Yu, K.; Hatanaka, T.; Hildebrand, D.F. Vernonia DGATs increase accumulation of epoxy fatty acids in oil. Plant Biotechnol. J. 2010, 8, 184-195. [CrossRef] [PubMed]

34. Xu, R.; Yang, T.; Wang, R.; Liu, A. Characterisation of DGAT1 and DGAT2 from Jatropha curcas and their functions in storage lipid biosynthesis. Funct. Plant Biol. 2014, 41, 321-329. [CrossRef]

35. Misra, A.; Khan, K.; Niranjan, A.; Nath, P.; Sane, V.A. Over-expression of JcDGAT1 from Jatropha curcas increases seed oil levels and alters oil quality in transgenic Arabidopsis thaliana. Phytochemistry 2013, 96, 37-45. [CrossRef] [PubMed]

36. Tao, Y.-B.; He, L.-L.; Niu, L.-J.; Xu, Z.-F. Isolation and characterization of an ubiquitin extension protein gene (JcUEP) promoter from Jatropha curcas. Planta 2015, 241, 823-836. [CrossRef] [PubMed]

37. Tao, Y.-B.; Hu, X.-D.; Xu, Z.-F. Fatty acid biosynthesis and triacylglycerol accumulation in the biofuel plant Jatropha curcas. In Jatropha, Challenges for a New Energy Crop; Mulpuri, S., Carels, N., Bahadur, B., Eds.; Springer: Singapore, 2019; pp. 163-179. [CrossRef]

38. Turchetto-Zolet, A.C.; Christoff, A.P.; Kulcheski, F.R.; Guilherm, L.-M.; Margis, R.; Marcia, M.-P. Diversity and evolution of plant diacylglycerol acyltransferase (DGATs) unveiled by phylogenetic, gene structure and expression analyses. Genet. Mol. Biol. 2016, 39, 524-538. [CrossRef]

39. Rosli, R.; Chan, P.L.; Chan, K.L.; Amiruddin, N.; Low, E.L.; Singh, R.; Harwood, J.L.; Murphy, D.J. In silico characterization and expression profiling of the diacylglycerol acyltransferase gene family (DGAT1, DGAT2, DGAT3 and WS/DGAT) from oil palm, Elaeis guineensis. Plant Sci. 2018, 275, 84-96. [CrossRef]

40. Yang, D.; Zhang, H.; Peng, K.; Chen, L.; He, H.; Huang, X.; Qin, J.; He, G.; Zhang, D. Differential gene regulation of lipid synthesis in the developing seeds of two biodiesel tree species, Jatropha and Vernicia. Int. J. Agric. Biol. 2016, 18, 1143-1152. [CrossRef]

41. Khan, K.; Kumar, V.; Niranjan, A.; Shanware, A.; Sane, V.A. JcMYB1, a Jatropha R2R3MYB transcription factor gene, modulates lipid biosynthesis in transgenic plants. Plant Cell Physiol. 2019, 60, 462-475. [CrossRef]

42. Chen, M.; Mooney, B.P.; Hajduch, M.; Joshi, T.; Zhou, M.; Xu, D.; Thelen, J.J. System analysis of an Arabidopsis mutant altered in de novo fatty acid synthesis reveals diverse changes in seed composition and metabolism. Plant Physiol. 2009, 150, 27-41. [CrossRef]

43. Bourgis, F.; Kilaru, A.; Cao, X.; Ngando-Ebongue, G.F.; Drira, N.; Ohlrogge, J.B.; Arondel, V. Comparative transcriptome and metabolite analysis of oil palm and date palm mesocarp that differ dramatically in carbon partitioning. Proc. Natl. Acad. Sci. USA 2011, 108, 12527-12532. [CrossRef]

44. Lu, S.; Sturtevant, D.; Aziz, M.; Jin, C.; Li, Q.; Chapman, K.D.; Guo, L. Spatial analysis of lipid metabolites and expressed genes reveals tissue-specific heterogeneity of lipid metabolism in high- and low-oil Brassica napus L. seeds. Plant J. 2018, 94, 915-932. [CrossRef]

45. Dinamarca, J.; Levitan, O.; Kumaraswamy, K.G.; Lun, D.S.; Falkowski, P. Overexpression of a diacylglycerol acyltransferase gene in Phaeodactylum tricornutum directs carbon towards lipid biosynthesis. J. Phycol. 2017, 53, 405-414. [CrossRef]

46. Hofvander, P.; Ischebeck, T.; Turesson, H.; Kushwaha, S.K.; Feussner, I.; Carlsson, A.S.; Andersson, M. Potato tuber expression of Arabidopsis WRINKLED1 increase triacylglycerol and membrane lipids while affecting central carbohydrate metabolism. Plant Biotechnol. J. 2016, 14, 1883-1898. [CrossRef] [PubMed]

47. Xu, X.; Vanhercke, T.; Shrestha, P.; Luo, J.; Akbar, S.; Konik-Rose, C.; Venugoban, L.; Hussain, D.; Tian, L.; Singh, S.; et al. Upregulated lipid biosynthesis at the expense of starch production in potato (Solanum tuberosum) vegetative tissues via simultaneous downregulation of ADP-Glucose Pyrophosphorylase and sugar dependent1 expressions. Front. Plant Sci. 2019, 10, 1444. [CrossRef] [PubMed]

48. Knothe, G. A technical evaluation of biodiesel from vegetable oils vs. algae. Will algae-derived biodiesel perform? Green Chem. 2011, 13, 3048-3065. [CrossRef] 
49. Durrett, T.P.; Benning, C.; Ohlrogge, J. Plant triacylglycerols as feedstocks for the production of biofuels. Plant J. $2008,54,593-607$. [CrossRef] [PubMed]

50. Graef, G.; LaVallee, B.J.; Tenopir, P.; Tat, M.; Schweiger, B.; Kinney, A.J.; Van Gerpen, J.H.; Clemente, T.E. A high-oleic-acid and low-palmitic-acid soybean: Agronomic performance and evaluation as a feedstock for biodiesel. Plant Biotechnol. J. 2009, 7, 411-421. [CrossRef]

51. Duffield, J.; Shapouri, H.; Graboski, M.; McCormick, R.; Wilson, R.U.S. biodiesel development: New markets for conventional and genetically modified agricultural products. Wash. DC USA Econ. Res. Serv. U. S. Dep. Agric. (USDA) 1998. [CrossRef]

52. Qu, J.; Mao, H.-Z.; Chen, W.; Gao, S.-Q.; Bai, Y.-N.; Sun, Y.-W.; Geng, Y.-F.; Ye, J. Development of marker-free transgenic Jatropha plants with increased levels of seed oleic acid. Biotechnol. Biofuels 2012, 5, 10. [CrossRef] [PubMed]

53. Maravi, D.K.; Kumar, S.; Sharma, P.K.; Kobayashi, Y.; Goud, V.V.; Sakurai, N.; Koyama, H.; Sahoo, L. Ectopic expression of AtDGAT1, encoding diacylglycerol O-acyltransferase exclusively committed to TAG biosynthesis, enhances oil accumulation in seeds and leaves of Jatropha. Biotechnol. Biofuels 2016, 9, 226. [CrossRef] [PubMed]

54. Andersson, M.X.; Dörmann, P. Chloroplast membrane lipid biosynthesis and transport. Plant Cell Monogr. 2009, 13, 125-156.

55. Kaup, M.T.; Froese, C.D.; Thompson, J.E. A role for diacylglycerol acyltransferase during leaf senescence. Plant Physiol. 2002, 129, 1616-1626. [CrossRef]

56. Correa, S.M.; Alseekh, S.; Atehortua, L.; Brotman, Y.; Rios-Estepa, R.; Fernie, A.R.; Nikoloski, Z. Model-assisted identification of metabolic engineering strategies for Jatropha curcas lipid pathways. Plant J. 2020, 104, 76-95. [CrossRef] [PubMed]

57. Tjellstrom, H.; Strawsine, M.; Ohlrogge, J.B. Tracking synthesis and turnover of triacylglycerol in leaves. J. Exp. Bot. 2015, 66, 1453-1461. [CrossRef]

58. Katavic, V.; Reed, D.W.; Taylor, D.C.; Ciblin, E.M.; Barton, D.L.; Zou, J.; MacKenzie, S.L.; Covello, P.S.; Kunst, L. Alteration of seed fatty acid composition by an ethyl methanesulfonate-induced mutation in Arabidopsis thaliana affecting diacylglycerol acyltransferase activity. Plant Physiol. 1995, 108, 399-409. [CrossRef]

59. Fu, Q.; Li, C.; Tang, M.; Tao, Y.B.; Pan, B.Z.; Zhang, L.; Niu, L.; He, H.; Wang, X.; Xu, Z.F. An efficient protocol for Agrobacteriummediated transformation of the biofuel plant Jatropha curcas by optimizing kanamycin concentration and duration of delayed selection. Plant Biotechnol. Rep. 2015, 9, 405-416. [CrossRef]

60. Ding, L.W.; Sun, Q.Y.; Wang, Z.Y.; Sun, Y.B.; Xu, Z.F. Using silica particles to isolate total RNA from plant tissues recalcitrant to extraction in guanidine thiocyanate. Anal. Biochem. 2008, 374, 426-428. [CrossRef]

61. Zhang, L.; He, L.L.; Fu, Q.T.; Xu, Z.F. Selection of reliable reference genes for gene expression studies in the biofuel plant Jatropha curcas using real-time quantitative PCR. Int. J. Mol. Sci. 2013, 14, 24338-24354. [CrossRef]

62. Ye, J.; Wang, C.; Sun, Y.; Qu, J.; Mao, H.; Chua, N.H. Overexpression of a transcription factor increases lipid content in a woody perennial Jatropha curcas. Front. Plant Sci. 2018, 9, 1479. [CrossRef] [PubMed]

63. Annarao, S.; Sidhu, O.P.; Roy, R.; Tuli, R.; Khetrapal, C.L. Lipid profiling of developing Jatropha curcas L. seeds using ${ }^{1} \mathrm{H}$ NMR spectroscopy. Bioresour. Technol. 2008, 99, 9032-9035. [CrossRef] [PubMed]

64. Tian, B.; Sun, M.; Jayawardana, K.; Wu, D.; Chen, G. Characterization of a PLD 22 homology gene from developing castor bean endosperm. Lipids 2020, 55, 537-548. [CrossRef] [PubMed]

65. Liu, Q.; Guo, Q.; Akbar, S.; Zhi, Y.; El Tahchy, A.; Mitchell, M.; Li, Z.; Shrestha, P.; Vanhercke, T.; Ral, J.P.; et al. Genetic enhancement of oil content in potato tuber (Solanum tuberosum L.) through an integrated metabolic engineering strategy. Plant Biotechnol. J. 2017, 15, 56-67. [CrossRef]

66. Wang, H.; Pan, J.; Li, Y.; Lou, D.; Hu, Y.; Yu, D. The DELLA-CONSTANS transcription factor cascade integrates gibberellic acid and photoperiod signaling to regulate flowering. Plant Physiol. 2016, 172, 479-488. [CrossRef] 